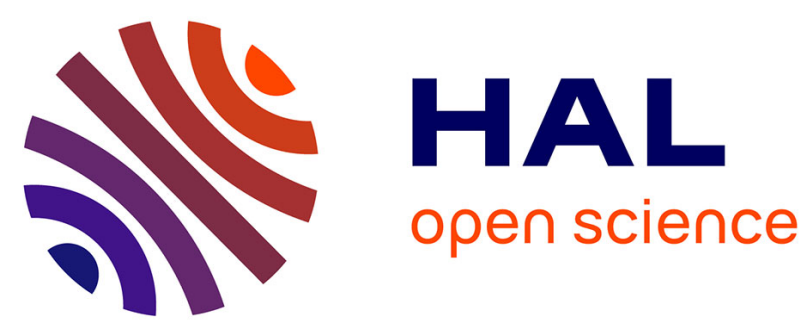

\title{
Mechanical properties and tribological behavior of a silica or/and alumina coating prepared by sol-gel route on stainless steel
}

\author{
Alexis Marsal, Florence Ansart, Viviane Turq, Jean-Pierre Bonino, \\ Jean-Michel Sobrino, Yan Min Chen, J. Garcia
}

\section{To cite this version:}

Alexis Marsal, Florence Ansart, Viviane Turq, Jean-Pierre Bonino, Jean-Michel Sobrino, et al.. Mechanical properties and tribological behavior of a silica or/and alumina coating prepared by sol-gel route on stainless steel. Surface and Coatings Technology, 2013, vol. 237, pp. 234-240. 10.1016/j.surfcoat.2013.06.037 . hal-01169755

\section{HAL Id: hal-01169755 \\ https://hal.science/hal-01169755}

Submitted on 30 Jun 2015

HAL is a multi-disciplinary open access archive for the deposit and dissemination of scientific research documents, whether they are published or not. The documents may come from teaching and research institutions in France or abroad, or from public or private research centers.
L'archive ouverte pluridisciplinaire HAL, est destinée au dépôt et à la diffusion de documents scientifiques de niveau recherche, publiés ou non, émanant des établissements d'enseignement et de recherche français ou étrangers, des laboratoires publics ou privés. 


\section{OATAO \\ Open Archive Toulouse Archive Ouverte}

\section{Open Archive TOULOUSE Archive Ouverte (OATAO)}

OATAO is an open access repository that collects the work of Toulouse researchers and makes it freely available over the web where possible.

This is an author-deposited version published in : http://oatao.univ-toulouse.fr/ Eprints ID : 14026

To link to this article : DOI:10.1016/j.surfcoat.2013.06.037

URL : http://dx.doi.org/10.1016/j.surfcoat.2013.06.037

To cite this version : Marsal, Alexis and Ansart, Florence and Turq, Viviane and Bonino, Jean-Pierre and Sobrino, Jean-Michel and Chen, Yan Min and Garcia, J. Mechanical properties and tribological behavior of a silica or/and alumina coating prepared by sol-gel route on stainless steel. (2013) Surface and Coatings Technology, vol. 237. pp. 234-240. ISSN 0257-8972

Any correspondance concerning this service should be sent to the repository administrator: staff-oatao@,listes-diff.inp-toulouse.fr 


\title{
Mechanical properties and tribological behavior of a silica or/and alumina coating prepared by sol-gel route on stainless steel
}

\author{
A. Marsal ${ }^{\text {a,b,* }}$, F. Ansart ${ }^{\text {a }}$, V. Turq ${ }^{\text {a }}$, J.P. Bonino ${ }^{\text {a }}$, J.M. Sobrino ${ }^{\text {b }}$, Y.M. Chen ${ }^{\text {b }}$, J. Garcia ${ }^{\text {b }}$ \\ a Université de Toulouse, Université Paul Sabatier, Institut Carnot CIRIMAT, 118 Route de Narbonne, 31062 Toulouse Cedex 09, France \\ b Institut Carnot CETIM (Technical center for the mechanical industry) 52, Avenue Félix Louat, BP 80067, 60304 Senlis Cedex, France
}

\begin{abstract}
A B S T R A C T
The increasing importance of developments in the mechanical industry requires a constant evolution of skills, particularly in the area of functionalization and protection of metallic alloy surfaces. The wear of materials is one of the causes of loss of profitability. This study aims to develop solutions to extend the lifetime of stainless steel $304 \mathrm{~L}$. In this work, we have achieved to optimize protective coatings on stainless steel against wear, using sol-gel method associated with dip-coating technique. Three routes have been proposed to achieve this type of coating, a single sol precursor of silica or alumina and a mixture of sols precursors of both oxides. The results of tribological tests show that silica coating does not provide a performance gain towards the stainless steel protection. Alumina coating even as thin film is very efficient to resist against wear. Wear track widths on the sample is reduced by a factor 2 , and the wear volume of the counterface is decreased by a factor 30 , corresponding to a total wear volume reduction of a factor 7 . The combination of both oxides seems to be a very promising way for such kind of application. With silica/alumina coating, we have obtained a reduction of widths wear track of a factor 1.5 and a decrease of friction coefficient as compared to alumina coating.
\end{abstract}

\section{Introduction}

The main objective in this study is to increase the durability of 304-L stainless steels with a protecting thin ceramic film. Thanks to their high hardness values, ceramic coatings would present the best properties to decrease wear. Apart from the conventional deposition ways such as PVD [1,2], CVD [3] or plasma sprayed [4-7], the sol-gel method is a new alternative process to develop coatings in order to improve the tribological behavior of the whole systems [8-16]. Indeed, many fields of material engineering use this method due to the advantages it offers. The sol-gel process allows the composition of the coating to be adjusted according to the intended application. For example, currently, the applications for sol-gel coatings are in the enhancement of adhesion, in anti-corrosion coatings, optical sensor and more recently, in the research developments for applications such as thermal barriers or high electrochemical performance films [17-21]. Here, the objective is to optimize the deposition parameters, and thus the nature and the structure of the coating to reduce wear. These parameters are dependent on the precursor concentration in the primary solution. It has also been proven that the final heat treatment conditions (temperature, atmosphere) play an important role on the nature and properties of the oxide film. Selected materials were silica- and alumina-based compounds, which are well known

\footnotetext{
* Corresponding author at: Université de Toulouse, Université Paul Sabatier, Institut Carnot CIRIMAT, 118 Route de Narbonne, 31062 Toulouse Cedex 09, France. E-mail address: marsal@chimie.ups-tlse.fr (A. Marsal).
}

to be good candidates to tackle wear because of their mechanical behavior [12,22-24]. The aim of this study is the optimization of the sol-gel synthesis of silica and/or alumina coatings on stainless steel $304 \mathrm{~L}$, to determine the best candidate materials in terms of tribological behavior and mechanical properties.

\section{Materials and methods}

\subsection{Materials}

AISI 304-L stainless steel disks of $30 \mathrm{~mm}$ in diameter and $5 \mathrm{~mm}$ in thickness were used as substrates. Pre-treatment of the surfaces of the samples was first done by grinding in order to obtain an average roughness $\left(R_{\mathrm{a}}\right)$ of $0.6 \mu \mathrm{m}$, followed by alkaline degreasing, acid pickling and finally nitric acid passivation of the surface.

\subsection{Coating processing on stainless steel substrates AISI $304 \mathrm{~L}$}

The preparation of silica and alumina sol-based coatings was performed as described below:

\subsubsection{Silica sol}

For the silica coating, the precursor used was an alkoxide, tetraethyl orthosilicate (TEOS). The sol was prepared [13] by mixing acetylacetone (AcAc) and water in ethanol at room temperature, followed by adding the required amount of TEOS and hydrochloric acid under stirring to obtain the proper concentration of TEOS. The volume fractions of TEOS, 
ethanol, hydrochloric acid, AcAc and water in the prepared solution are $7 / 89.5 / 0.5 / 2 / 1$, respectively. After stirring of the mixed solution at room temperature for $0.5 \mathrm{~h}$, a transparent solution was obtained, which was then aged for $24 \mathrm{~h}$ and used for film preparation. The viscosity of silica sol is around $7 \mathrm{MPa} \cdot \mathrm{s}$ during deposition. The silica coatings were shaped by a dip-coating method with a withdrawal speed of $300 \mathrm{~mm} \mathrm{~min}^{-1}$. The films were dried for $2 \mathrm{~h}$ at $80{ }^{\circ} \mathrm{C}$ and then densified by thermal treatment under air for $25 \mathrm{~min}$ at $500{ }^{\circ} \mathrm{C}$ with heating rate of $100{ }^{\circ} \mathrm{C} / \mathrm{h}$. A scanning of the TEOS concentration in the sol was performed in the range of 0.17 to $1.66 \mathrm{~mol} \mathrm{~L}^{-1}$.

\subsubsection{Alumina sol}

The alumina precursor is a metal salt. An excess of ammonia solution ( $5 \mathrm{~mol} \mathrm{~L}^{-1}$ ) was firstly dripped into an aqueous aluminum chloride solution $\left(0.13 \mathrm{~mol} \mathrm{~L}^{-1}\right)$ at room temperature until a $\mathrm{pH}$ value of 9 was reached. The obtained compound was then filtered and washed with hot distilled water. The cleaned hydrated precipitate was aged for $72 \mathrm{~h}$ in a drying oven at $85{ }^{\circ} \mathrm{C}$. After drying, the precipitate consists of boehmite (Fig. 1), and a known amount of the boehmite was dispersed in distilled water. The solution was peptized with a $12.5 \mathrm{vol} \%$ of acetic acid (100\%) and then stirred for $24 \mathrm{~h}$ to obtain a colloidal dispersion. Next, an addition of PEG (Molecular Weight $=400 \mathrm{~g} \mathrm{~mol}^{-1}$ ) with a volume fraction of $1.5 \%$ was done and a new maturation of $24 \mathrm{~h}$ with magnetic stirring was necessary. A deposition was made by dip coating with a withdrawal of $300 \mathrm{~mm} \mathrm{~min}^{-1}$. The films were then dried and densified under the same conditions as for silica films. XRD studies on alumina xerogel have shown a phase transformation from boehmite to gamma alumina. By adjusting the amount of boehmite in the present medium, a scanning of the boehmite concentration was performed in the range of 0.17 to $1.60 \mathrm{~mol} \mathrm{~L}^{-1}$.

\subsection{Characterization techniques}

Several techniques allow the determination of the surface properties of samples. The measurements of contact angles were carried out with a goniometer GBX Digidrop using deionized water $(2.5 \mu \mathrm{L})$. The roughness of the substrate was measured with a Bruker's NPFLEX ${ }^{\mathrm{TM}} 3 \mathrm{D}$ Surface Metrology white light interferometry. With this technique, it is also possible to determine a wear surface. Ten measurements were performed on each sample to obtain an average wear profile along the track. Then, the total wear volume was determined by multiplying the wear profile by the circumference of the worn track. The wear width was determined by optical microscopy Keyence VHX-1000E, while the wear volume of the ball was obtained by calculation of the spherical cap measured by white light interferometry.

The rheological analysis of sols was made by a viscometer Rheomat RM100 of type Taylor-Couette flow at a shear range of 200-3867 s $\mathrm{s}^{-1}$. Structural analyses of the thermal-treated xerogels were performed with X-ray diffractometer BRUKER D4 ENDEAVOR. XRD patterns were collected at room temperature by scanning steps of $0.02^{\circ}(2 \theta)$ over a $10.00^{\circ}<2 \theta<100.00^{\circ}$ angular range and using a $\mathrm{Cu} \mathrm{K} \alpha$ radiation $(0.15418 \mathrm{~nm})$.

Thickness of films was determined by Scanning Electron Microscopy (SEM) JEOL JSM 6400 on cross-sectional images or by a DEKTAK 3030ST (VEECO) mechanical profilometer. Adhesive properties of films were evaluated by a Nano-Scratch tester (NST, CSM Instruments) to measure critical loads of crack formation or delamination. Scratch tests were performed with a loading rate of $13 \mathrm{mN} \mathrm{min}^{-1}$ and a maximum normal load of $100 \mathrm{mN}$. Three scratches were performed on each sample. Tribological evaluation was carried out by uni-directional sliding test on a pin-on-disk tribometer (CSEM Instruments) under ambient environment. This test is based on the international standard ASTM G99, which simulates the wear issue found in mechanical industry. The pin was a 316-L stainless steel ball with a diameter of $10 \mathrm{~mm}$. Normal loading force was $2 \mathrm{~N}$ and sliding distance was $250 \mathrm{~m}$. Tests were made at a sliding velocity of $10 \mathrm{~cm} \mathrm{~s}^{-1}$, within a circular diameter of $20 \mathrm{~mm}$ on the samples. Three tests were systematically done on each sample.

\section{Results and discussion}

\subsection{Surface preparation on AISI 304-L stainless steel}

After mechanical grinding of the substrate surface to an average $R_{\mathrm{a}}$ value of $0.6 \mu \mathrm{m}$, several chemical treatments were tested in order to enhance the surface wettability (Fig. 2). All the samples were degreased by using alkaline solution, and then two types of picklings (either fluonitric or sulfuric) were applied. In the case of sulfuric pickling, two immersion durations have been tested. The effect of passivation on the surface from these two types of pickling has also been studied. Chemical preparation does not affect the roughness of the substrate which remains at an $R_{\mathrm{a}}$ value of $0.6 \mu \mathrm{m}$. Fig. 2 showed that the fluonitric stripping did not confer to satisfactory standards in terms of wettability; on the contrary, sulfuric stripping provided an appropriate surface. For economical reasons, 7 min of stripping was chosen. In view to facilitate easy handling and to avoid excessive surface reactivity, we decided to passivate the surface.

\subsection{Silica coating}

After the analysis of the surface topography as well as the rheological study of the sol, homogeneous coating is derived from a sol with a molar concentration of $0.88 \mathrm{~mol} \mathrm{~L}^{-1}$. Profilometry measurements show that the thickness of silica coating was around $1 \mu \mathrm{m}$. The tribological behavior of the silica-coated sample has been compared to the one of the pristine substrate without surface preparation and also to one of the substrates which has undergone both surface preparation

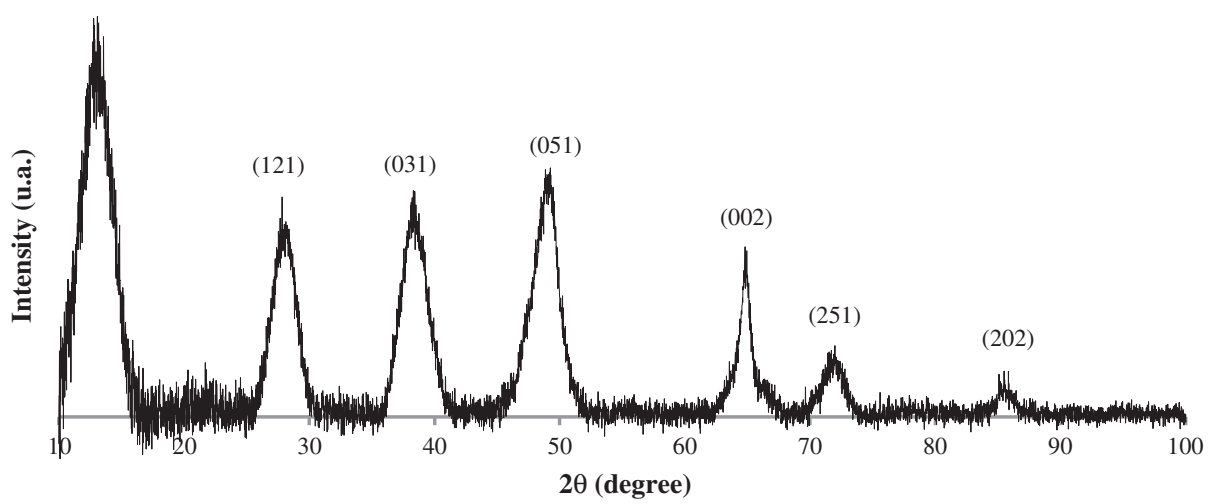

Fig. 1. X-ray pattern of the boehmite after drying at $85{ }^{\circ} \mathrm{C}$ (JCPDS card 00-021-1307). 
Without passivation

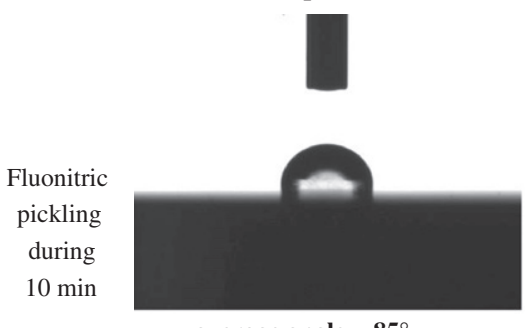

average angle $=85^{\circ}$

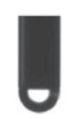

Sulfuric

pickling

during

$7 \mathrm{~min}$

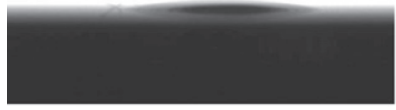

average angle $<10-15^{\circ}$

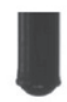

Sulfuric

pickling

during

$15 \min$

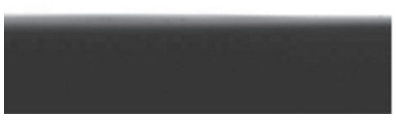

average angle $<10-15^{\circ}$
With passivation

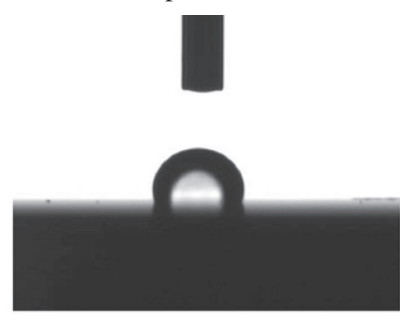

average angle $=92^{\circ}$
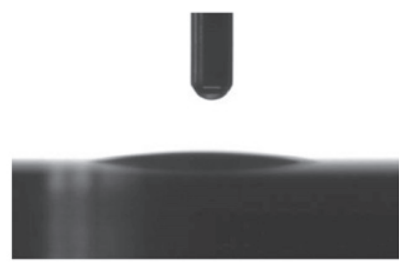

average angle $<10-15^{\circ}$

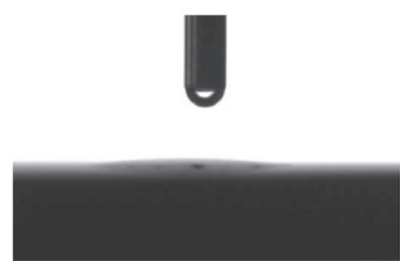

average angle $<10-15^{\circ}$

Fig. 2. Influence of pickling on the measurement of the contact angle of a water drop on AISI $304 \mathrm{~L}$.

and heat treatment. Fig. 3 shows the friction coefficients of samples as a function of the sliding distance, at $2 \mathrm{~N}$ of normal load in unidirectional sliding test against stainless steel ball with $10 \mathrm{~mm}$ of diameter. All tests show good reproducibility. For uncoated samples, without surface preparation (Fig. 3a), there is a short transitional period of $50 \mathrm{~m}$. During this period, the friction coefficient is very noisy, increasing from 0.2 to 0.7 , and stabilizes at this value until $250 \mathrm{~m}$, but the noisy signal is maintained. For the sample that has undergone the double preparation (chemical and thermal) (Fig. 3b), the friction coefficient stabilizes after a similar sliding distance and at a similar value. The observed differences could be due to the native oxide layer on the pristine substrate. Fig. 4 presents the evolution of friction coefficient for a silica-coated sample. Despite the addition of the silica coating, there is a similar friction coefficient with disturbed signal, but we could not observe a transitional period of lapping. As shown in Fig. 5b, the coating is completely worn after the tribological test. In this test, the ball rubs on the substrate with a friction coefficient

(a)

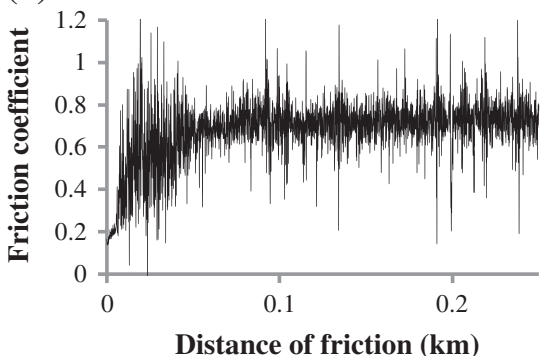

of about 0.7 , which is a characteristic value of friction between the stainless steel ball and the uncoated stainless steel substrate. These results were correlated with the wear of the counterface after the tribological test, which is measured from the optical images of the worn ball surface and from the topographical images obtained by interferometry. The worn surface of the sample and that of the counterface (worn ball) are similar for uncoated sample and silica-coated sample (Fig. 5). In both cases, there is a large width track of the same order of magnitude of $2300 \mu \mathrm{m}$ (slightly lower for the coated sample system), which also corresponds to the wear diameter measured on the ball. This important wear could also explain the noise on the measured friction coefficient signal. A more precise analysis of the surface of ball has been done by white light optical interferometry (Fig. 6). This corresponds to a counterface wear volume of $0.31 \mathrm{~mm}^{3}$ for uncoated sample and $0.26 \mathrm{~mm}^{3}$ for a silica sample coating. This insignificant difference between the volumes of wear is in good agreement with the other observations and with the stabilization at the same value of friction coefficient (0.7). This study (b)

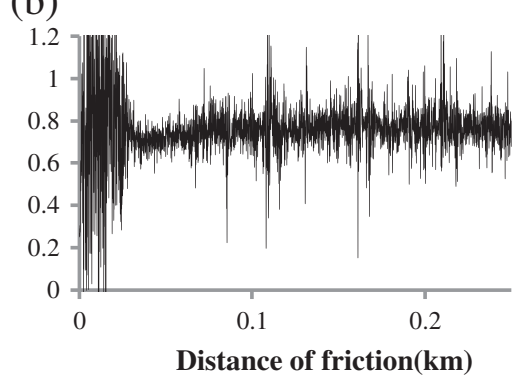

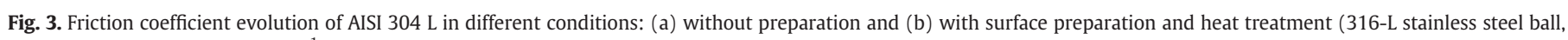
$\varnothing 10 \mathrm{~mm}, \mathrm{~F}=2 \mathrm{~N}, \mathrm{~V}=10 \mathrm{~cm} \mathrm{~s}^{-1}$ ). 


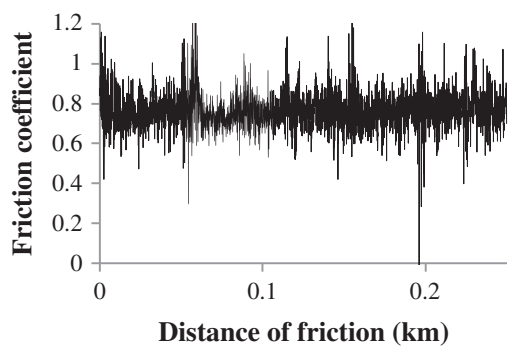

Fig. 4. Friction coefficient evolution for a sample with silica coating deposited on AISI $304 \mathrm{~L}$ (316-L stainless steel ball, $\varnothing 10 \mathrm{~mm}, \mathrm{~F}=2 \mathrm{~N}, \mathrm{~V}=10 \mathrm{~cm} \mathrm{~s}^{-1}$ ).

shows us that the only silica coating does not effectively improve the performance of wear resistance of stainless steel.

\subsection{Alumina coating}

First, a stable and reproducible alumina sol was prepared. After optical microscopy observations of deposits with a concentration from 0.17 to $1.66 \mathrm{~mol} \mathrm{~L}^{-1}$, we focus on the range between 1 and $1.45 \mathrm{~mol} \mathrm{~L}^{-1}$. For coatings with a concentration of $1.45 \mathrm{~mol} \mathrm{~L}^{-1}$ and more, we notice the presence of heterogeneities on the optical micrograph (Fig. 7a). From the electronic micrograph presented on Fig. 7b, we attribute these heterogeneities to the presence of alumina agglomerates. The presence of these defaults is related to the poor stability of the sol. Indeed, a rheological study shows that for a concentration of $1.45 \mathrm{~mol} \mathrm{~L}^{-1}$ (or higher concentration, results not shown), the behavior is not the one of a Newtonian fluid (Fig. 8). Based on the previous study, in order to have a coating with uniform surface, a good compromise would be a sufficient thickness that can be reached for a maximum concentration of boehmite in the sol of $1.30 \mathrm{~mol} / \mathrm{L}$. We then obtain a 3- $\mu$ m-thick coating (Fig. 9).

\subsubsection{Tribological behavior}

For alumina-coated sample, we observe on the friction curve (Fig. 10) a short transitional period of $50 \mathrm{~m}$ during which the friction coefficient increases from 0.8 to 1.1 and then decreases to 1 . Friction coefficient stabilizes at this value until $250 \mathrm{~m}$. In this case, there is a different behavior between an uncoated (Fig. 3) sample and aluminacoated sample. The friction coefficient stabilizes at 1 for the sample coated against 0.7 for that of the uncoated one. As we can also observe on Fig. 11, another difference on the wear track of the two antagonist bodies since a less important wear appears on the alumina-coated
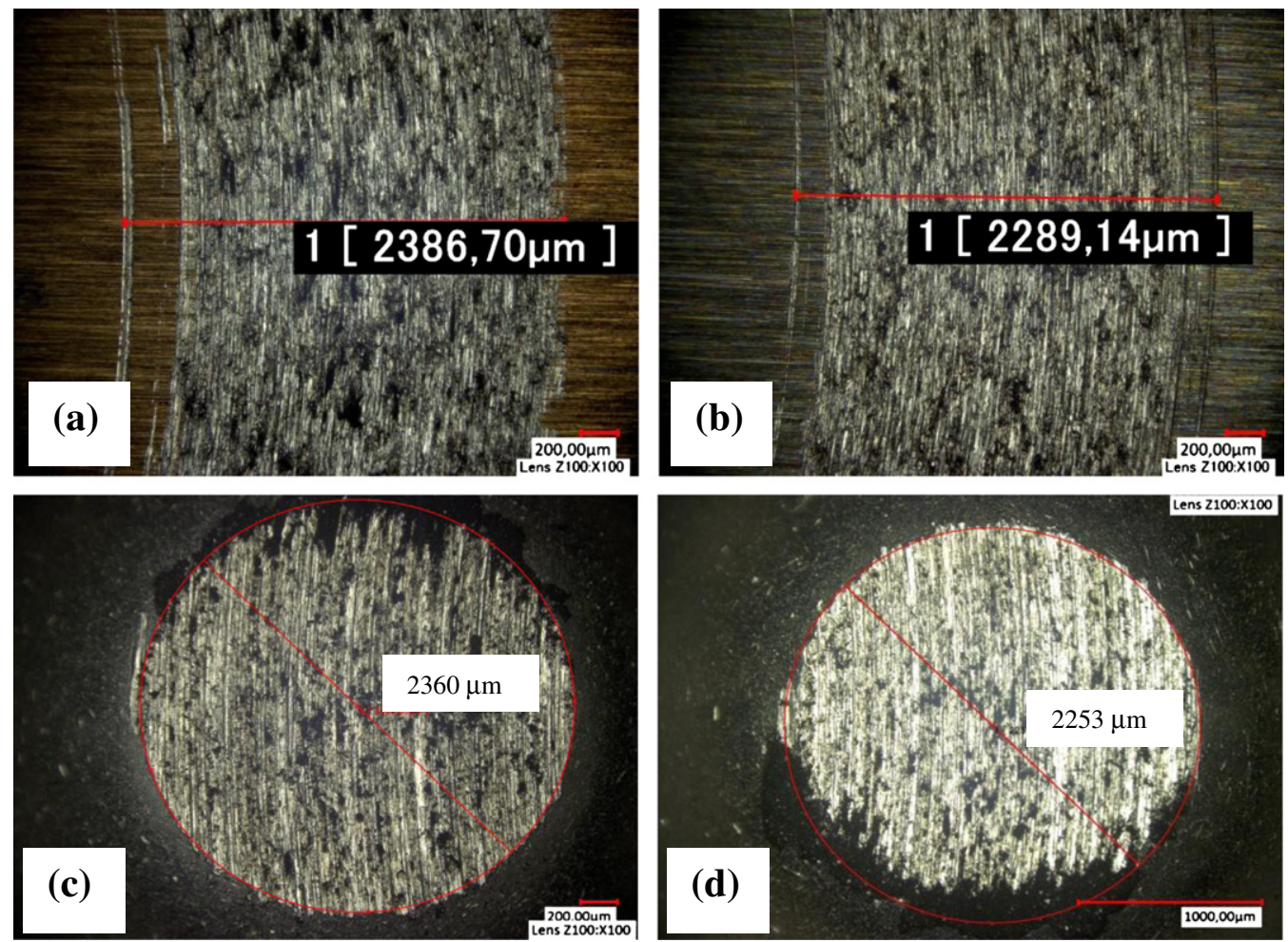

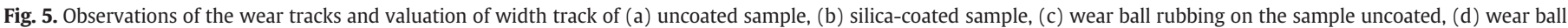
rubbing on silica-coated sample, after $250 \mathrm{~m}$ of sliding (316-L stainless steel ball, $\varnothing 10 \mathrm{~mm}, \mathrm{~F}=2 \mathrm{~N}, \mathrm{~V}=10 \mathrm{~cm} \mathrm{~s}$ ).
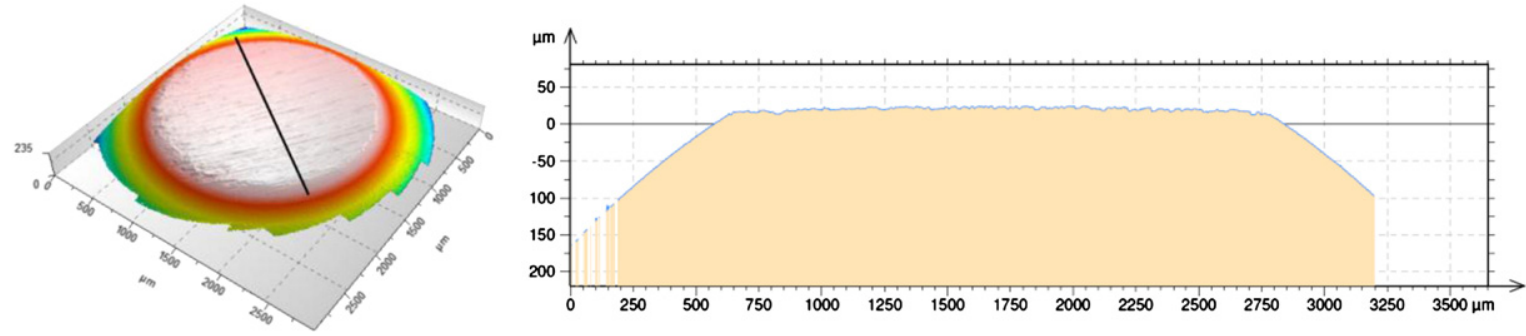

Fig. 6. Topographical analysis of the wear surface of a ball after the tribological tests on silica-coated sample (316-L stainless steel ball, $\varnothing 10 \mathrm{~mm}, \mathrm{~F}=2 \mathrm{~N}, \mathrm{~V}=10 \mathrm{~cm} \mathrm{~s}{ }^{-1}$ ). 

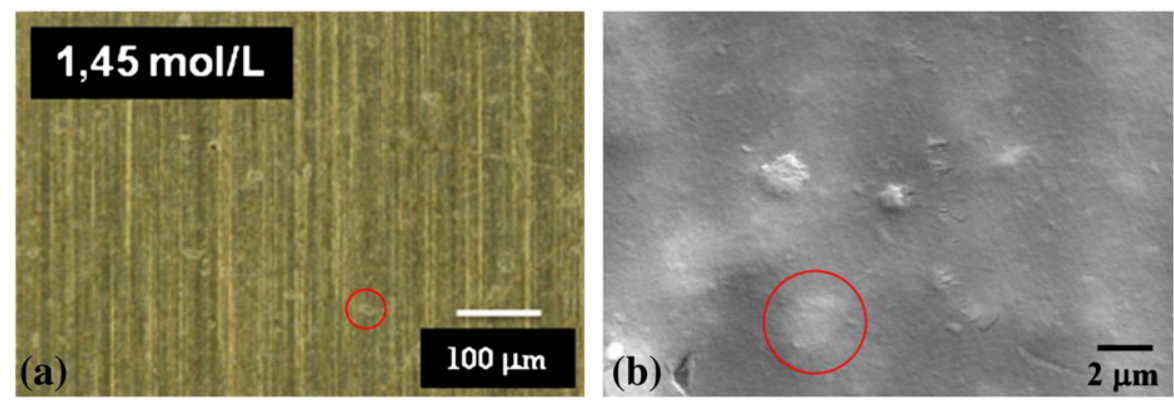

Fig. 7. Optical (a) and electron (b) microscopy micrographs of the surface of alumina coating obtained from a sol concentration of 1.45 mol $\mathrm{L}^{-1}$ of boehmite.

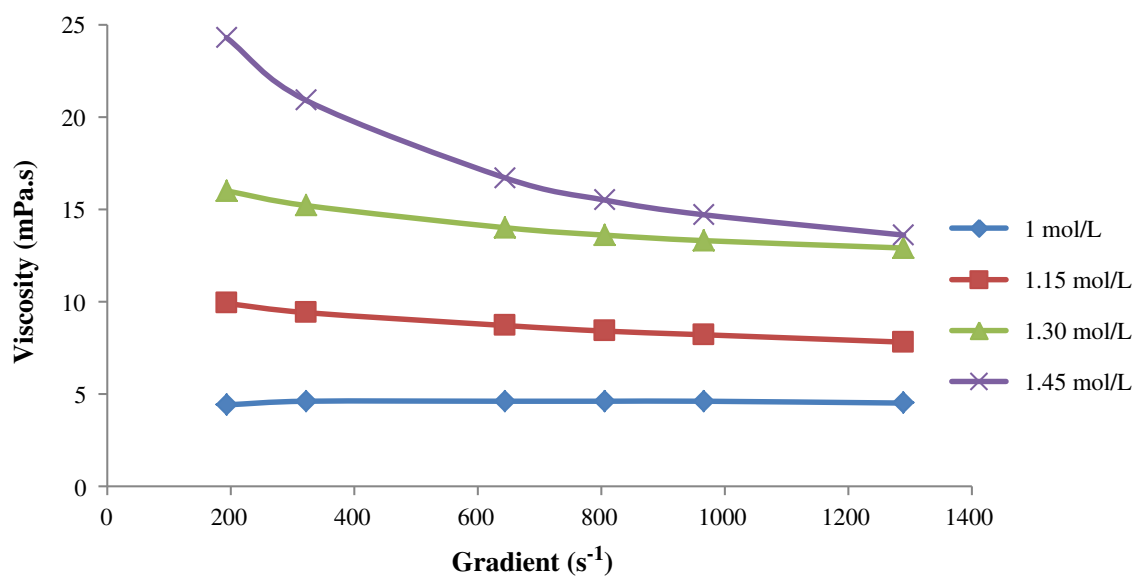

Fig. 8. Rheological behavior depending on the boehmite concentration in the sol.

sample and the ball. Wear track width on the sample is reduced in this case by a factor 2 , and the wear volume of the counterface decreases from 0.31 to $0.01 \mathrm{~mm}^{3}$; the reduction of wear is therefore of a factor 30. This different behavior can be explained by the fact that the coating protects the contact between the substrate and the ball. From a chemical mapping by EDS analysis of the surface of wear track reported on Fig. 12, the presence of aluminum is still observed (red marks) after $250 \mathrm{~m}$ of sliding corresponding to 3970 cycles.

\subsubsection{Mechanical properties}

The adhesion of the coatings has been evaluated with nanoscratch test by measuring the critical normal loads from the plastic deformations. All test parameters are kept constant for each sample. Microscopic

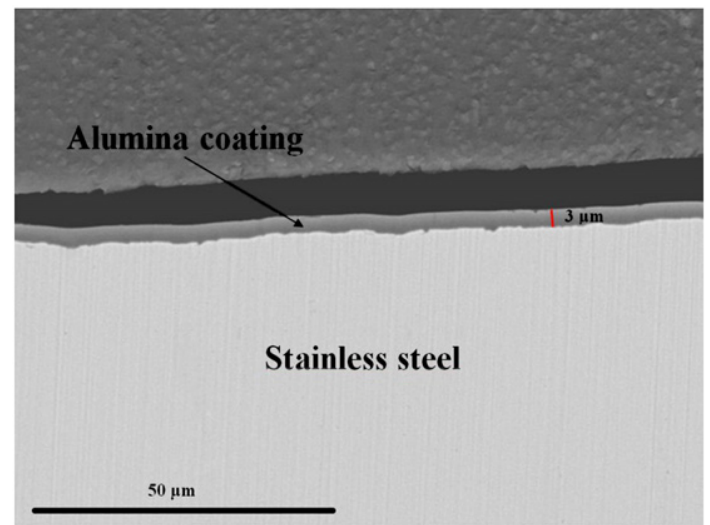

Fig. 9. Sectional electron micrograph of alumina coatings deposited on 304-L stainless steel. observations after nanoscratch tests of the coatings are reported in Fig. 13.

Plastic deformation occurs from the first contact at the minimal normal load $(0.3 \mathrm{mN})$ between the indenter and the surface of the coating. Rapidly, Hertz circle cracking appears ( $2 \mathrm{mN}$ ) as on Fig. 13b, followed by chevron crack propagation in the scratch $(4 \mathrm{mN})$. The first cracking propagation outside the scratch occurs at $45 \mathrm{mN}$ as on Fig. 13d. This propagation continues until the applied normal load of $100 \mathrm{mN}$ is reached (Fig. 13f). This study shows that the coating damage remains localized on the scratch without total delamination which confirms a good coating adhesion on the substrate.

\subsection{Silica/alumina coating}

The alumina coating proves its effectiveness against wear, but it would be interesting to combine this function with a decrease of friction coefficient. Hence, among the prospects we planned, the creation of a sol-gel mixed (alumina/silica) is proposed to couple the anti-wear

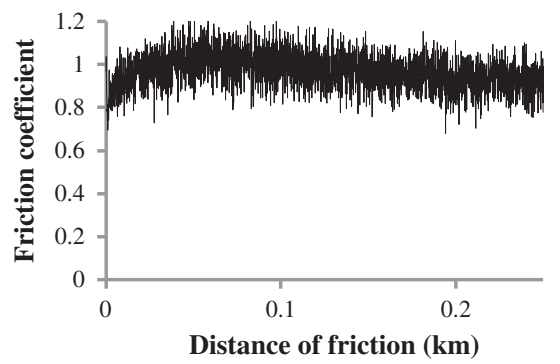

Fig. 10. Friction coefficient evolution for a sample with alumina coating deposited on AISI 304-L stainless steel (316-L stainless steel ball, $\varnothing 10 \mathrm{~mm}, \mathrm{~F}=2 \mathrm{~N}, \mathrm{~V}=10 \mathrm{~cm} \mathrm{~s}^{-1}$ ). 

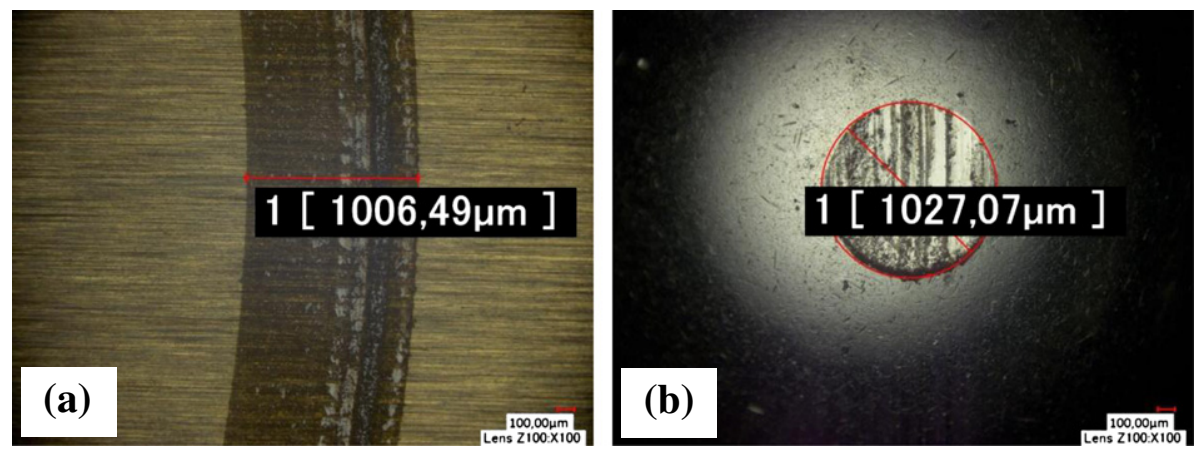

Fig. 11. Observations of the wear tracks and evaluation of (a) width track of the alumina-coated sample and (b) of the wear diameter of the ball after $250 \mathrm{~m}$ of sliding (316-L stainless steel ball, $\varnothing 10 \mathrm{~mm}, \mathrm{~F}=2 \mathrm{~N}, \mathrm{~V}=10 \mathrm{~cm} \mathrm{~s}^{-1}$ ).
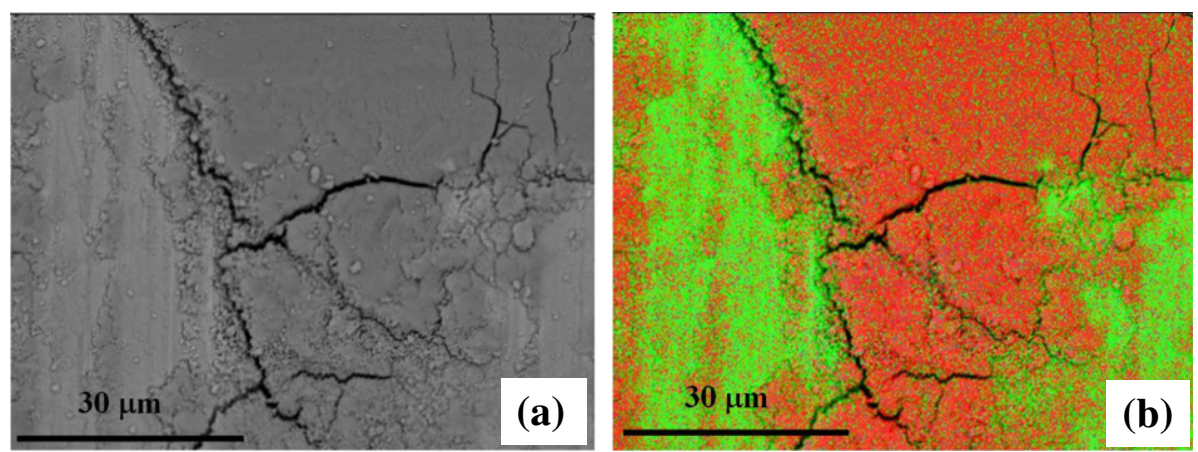

Fig. 12. Scanning electron micrograph (BSE) and chemical mapping (Al: red and Fe: green) by EDS analysis of the friction track after $250 \mathrm{~m}$ of sliding (3970 cycles).

properties of alumina and the ability to lubricate the contact of silica [25]. In this context, the previous alumina precursor remains unchanged. On the other side, to ensure a good stability of the mixed sol, thanks to its organic function, the GPTMS alkoxide ((3-glycidyloxypropyl) trimethoxysilane) was chosen for the silica precursor in the sol. For the first studies, a molar ratio of $50 \%$ aluminum and $50 \%$ silicon is kept constant. After stirring of the mixed solution at room temperature for $24 \mathrm{~h}$, the viscosity of mixed sol is around $14 \mathrm{MPa} \cdot \mathrm{s}$ during deposition. The mixed coatings are shaped by dip-coating method with a withdrawal speed equal to $50 \mathrm{~mm} \mathrm{~min}^{-1}$. After heat treatment, we obtain thickness of coating around $1.20 \mu \mathrm{m}$ (Fig. 14). A study of the tribological behavior, as described previously, would allow us to evaluate the influence of the quantity of silicon introduced in the coating (Fig. 15). The first prepared mixed coating allows to reduce the friction coefficient of the first $25 \mathrm{~m}$ of sliding: For the first cycles, there is a friction coefficient of 0.5 before it gradually increases until a stabilization to around 1. After the first 25 meters, the behavior is similar to that of a contact of stainless steel ball with alumina coating. The anti-wear property remains unchanged. The width track and the wear of the ball of $0.01 \mu \mathrm{m}^{3}$ is on the same order of magnitude as for the alumina coating. However, for the mixed coating, we observe that the signal is less disturbed than that of the silica and alumina coatings throughout the test.

\section{Conclusion}

Silica, alumina and mixed silica/alumina coatings were deposited onto stainless steel from sols prepared, respectively, from TEOS, boehmite and a mixture of boehmite/GPTMS. The influence of coating on tribological behavior has been investigated. The results of tribological tests show that alumina coating even as thin film is very efficient to resist against wear, while a silica coating does not provide a performance

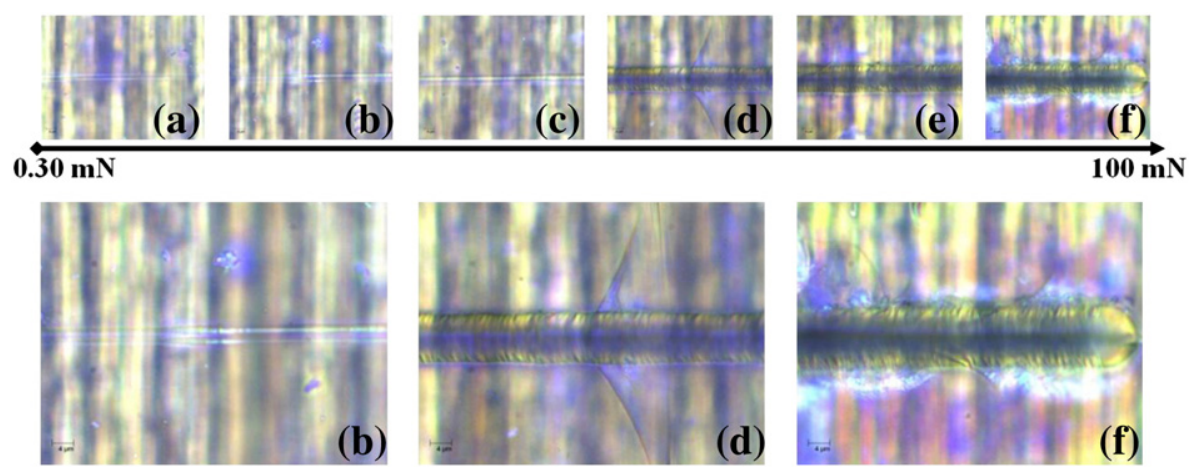

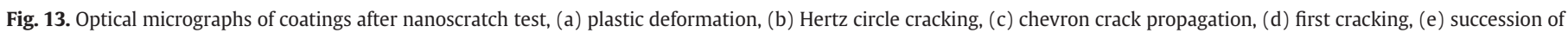
craking and (f) maximum normal force applied without delamination. 


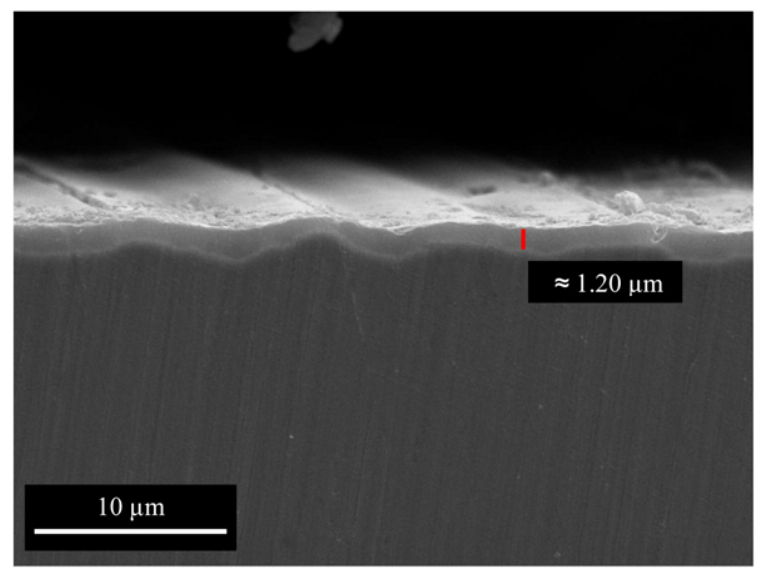

Fig. 14. Sectional electron micrograph of mixed coatings deposited on 304-L stainless steel.

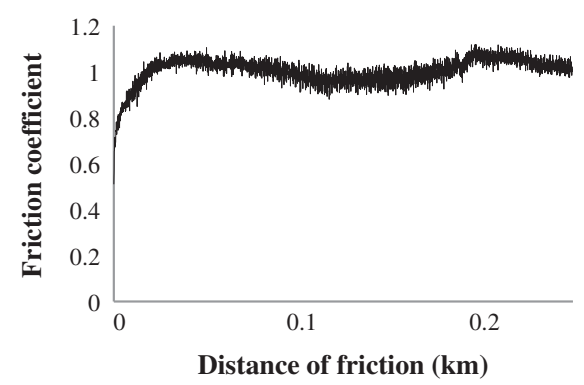

Fig. 15. Friction coefficient evolution for a mixed silica/alumina coating deposited on AISI 304-L stainless steel (316-L stainless steel ball, $\varnothing 10 \mathrm{~mm}, \mathrm{~F}=2 \mathrm{~N}, \mathrm{~V}=10 \mathrm{~cm} \mathrm{~s}^{-1}$ ).

gain towards the stainless steel protection. From a quantitative point of view, deposition of an alumina coating induced a wear reduction of the ball by a factor 30 and a total wear reduction by a factor 7 . At the same time, a good adhesion was shown between the coating and the steel. After more severe tests performed by scratch, when damage occurs on the coating, it was localized on the scratch, and no cracking propagation or even no delamination of the coating was observed. Thus, the structure of the coating is preserved over a large surface and allows us to create a sustainable protective interface between the stainless steel ball and stainless steel substrate. Nonetheless, the friction coefficient remains high and constant. To tackle this issue, a preliminary work was done on a mixed alumina and silica coating and results are promising as we note a reduction in the friction coefficient at the beginning of measurements, without reducing the anti-wear properties of the coating. This work is now in progress in the attempt to develop a bifunctional system using this low cost process.

\section{References}

[1] C. Martini, L. Ceschini, Tribol. Int. 44 (2011) 297

[2] U. Wiklund, M. Larsson, Wear 241 (2000) 234.

[3] P. Gupta, V. Singh, E.I. Meletis, Tribol. Int. 37 (2004) 1019.

[4] M. Gui, S.B. Kang, Mater. Lett. 51 (2001) 396.

[5] P. Ananthapadmanabhan, T. Thiyagarajan, K. Sreekumar, R. Satpute, N. Venkatramani, K. Ramachandran, Surf. Coat. Technol. 168 (2003) 231.

[6] P. Fauchais, A. Vardelle, A. Denoirjean, Surf. Coat. Technol. 97 (1997) 66.

[7] H.-K. Kang, S.B. Kang, Mater. Sci. Eng. A 428 (2006) 336.

[8] W. Zhang, W. Liu, C. Wang, J. Eur. Ceram. Soc. 22 (2002) 2869.

[9] S. Wilson, H. Hawthorne, Q. Yang, T. Troczynski, Surf. Coat. Technol. 133-134 (2000) 389 .

[10] T. Hübert, J. Schwarz, B. Oertel, J. Sol-Gel Sci. Technol. 38 (2006) 179.

[11] I. Piwoński, K. Soliwoda, Ceram. Int. 36 (2010) 47.

[12] W. Zhang, Sci. China, Ser. B Chem. 45 (2002) 84.

[13] W. Zhang, Appl. Surf. Sci. 185 (2001) 34.

[14] J.P. Grobelny, G. Celichowski, M. Cichomski, A.J. Kulik, I.J. Piwoński, S. Plaza, Tribol. Lett. 16 (2004) 181.

[15] J. Ballarre, D.A. López, A.L. Cavalieri, Thin Solid Films 516 (2008) 1082.

[16] G. Celichowski, I. Piwonski, M. Cichomski, K. Koralewski, S. Plaza, W. Olejniczak, J. Grobelny, Tribol. Lett. 14 (2003) 181.

[17] D.C. Vasconcelos, J.A. Carvalho, M. Mantel, W. Vasconcelos, J. Non-Cryst. Solids 273 (2000) 135

[18] P. Innocenzi, M. Esposto, A. Maddalena, J. Sol-Gel Sci. Technol. 20 (2001) 293.

[19] J.-B. Cambon, J. Esteban, F. Ansart, J.-P. Bonino, V. Turq, S.H. Santagneli, C.V Santilli, S.H. Pulcinelli, Mater. Res. Bull. 47 (2012) 3170.

[20] E. Certhoux, F. Ansart, V. Turq, J.P. Bonino, J.M. Sobrino, J. Garcia, J. Reby, Prog. Org. Coat. 76 (2013) 165.

[21] J. Fenech, M. Dalbin, A. Barnabe, J.P. Bonino, F. Ansart, Powder Technol. 208 (2011) 480

[22] W. Zhang, W. Liu, C. Wang, Ceram. Int. 29 (2003) 427.

[23] D.R. Cairns, A.J. Kessman, P.J. Richter, F.J. Bottari, N.X. Randall, Wear 265 (2008) 411

[24] T. Hübert, S. Svoboda, B. Oertel, Surf. Coat. Technol. 201 (2006) 487.

[25] J. Rams, A.J. Lopez, M.D. Lopez, A. Ureña, Surf. Coat. Technol. 202 (2007) 1144 